\title{
FORMAÇÃO DE PROFESSORES DA EDUCAÇÃO INFANTIL: UM PARALELO ENTRE AS DIRETRIZES NACIONAIS DO BRASIL E A ABORDAGEM REGGIO EMILIA DA ITÁLIA
}

\author{
ANA PAULA DE OLIVEIRA ITEN ${ }^{1}$ \\ THYARA ANTONIELLE DEMARCHI \\ RITA BUZZI RAUSCH ${ }^{3}$
}

\section{INTRODUÇÃO}

Este artigo tem o propósito de refletir sobre a formação de professores da Educação Infantil, no Brasil, trazendo contribuições da abordagem Reggio Emilia, no qual tange reflexões sobre as atribuições docentes na Educação Infantil.

Esta pesquisa tem como ponto de partida a questão problema: qual a relação entre as diretrizes que orientam a formação de professores da Educação Infantil no Brasil e na abordagem italiana Reggio Emilia? Trazemos no estudo ideias e impasses na formação docente tanto no Brasil quanto na Itália, a partir da análise de documentos, livros a respeito da abordagem Reggio Emilia e da formação no Brasil e, além disso, sobre a história que cada um desses países passou para chegar onde a Educação se encontra atualmente.

Alicerçamo-nos na abordagem de aspectos e novas proposições para a formação docente, principalmente em Kramer (2005), trazendo também a análise dos processos históricos. Para amparar nossos estudos também contamos com as pesquisas de Nóvoa (2002 e 2011), Kishimoto (2002), Tardif (2010) entre outros. Nos levantamentos feitos da abordagem italiana utilizamos os estudos de Gandini (2002) e Edwards (1999), trazendo considerações sobre a história das escolas italianas, as dificuldades que apresentaram para se reerguer, a formação contínua dos profissionais de educação e quais as exigências de formação acadêmica para lecionar na educação infantil italiana.

Na primeira parte deste artigo, apresentamos como a formação docente no Brasil foi marcada por diferentes movimentos, aspectos históricos que continuam por marcar a profissão professor na atualidade, trazendo como primeiro subtítulo: “A consolidação da Educação Infantil no Brasil e sua formação docente.” Na segunda parte fazemos um breve relato sobre a abordagem Reggio Emilia, tempos históricos de construção da

1. Pedagoga graduada pela Universidade Regional de Blumenau - FURB. Especialista em O ensino da Arte na Educação Básica. Aluna Especial do Mestrado em Educação da FURB.

2. Pedagoga graduada pela Universidade Regional de Blumenau - FURB. Aluna Especial do Mestrado em Educação da FURB.

3.Doutora em Educação Pela UNICAMP. Professora/pesquisadora do Programa de Pós-Graduação em Educação. 
mesma e como se dá o processo de formação de professor, o que é exigido para lecionar em escolas de Educação Infantil e quais as formas de incentivo para continuar a estudar. Finalmente, a última parte deste estudo se configura numa análise dos aspectos de formação em ambos os países, trazendo questionamentos, indagações, comparações, reflexões sobre a história da educação no Brasil e Itália, e buscando a resposta da questão problema.

Pretende-se mostrar, portanto, como a formação de professores, especialmente a formação continuada são importantes para o desenvolvimento profissional docente, buscando aproximações com propostas pedagógicas bem sucedidas de outros países, no intuito de refletirmos acerca de possíveis avanços necessários à sua qualificação no país.

\section{A CONSOLIDAÇÃO DA EDUCAÇÃO INFANTIL NO BRASIL E SUA FORMAÇÃO DOCENTE}

A formação de professores no Brasil é marcada por diferentes movimentos com uma cronologia ligada aos acontecimentos políticos. Está presente nos discursos governamentais a fim de buscar a qualidade da educação.

Diante deste contexto, é fundamental buscarmos aspectos históricos que nos proporcionam elementos para que possamos compreender melhor a situação contemporânea da formação dos professores na Educação Infantil. A importância de analisarmos o processo histórico é também apontado por Nóvoa (2002, p.14):

\footnotetext{
Sem um pensamento histórico e filosófico cairemos na agitação das palavras e dos instantes. É a pior maneira de travar um debate educativo. Instinto, por isso, na necessidade de incorporar a nossa reflexão na história, de nos incorporarmos na história. Não para que dela fiquemos prisioneiros: a história não é uma fatalidade, é uma possibilidade. Mas para que, a partir dela, saibamos encontrar novos caminhos para dizer a nossa intenção de educar.
}

Neste sentido não podemos descartar o que já foi conquistado e quais as possíveis conquistas que poderão ser alcançadas. As políticas educativas voltadas para as crianças no Brasil só começaram a surgir, segundo Kramer (2005), na década de 80 e ganharam forças com a Constituição de 1988. Especificamente no artigo 208, inciso IV em que aponta que o dever do Estado para com a educação será efetivado mediante a garantia de atendimento em creches e pré-escolas às crianças de zero a seis anos de 
idade. E também a mesma Constituição determina que os municípios atuarão prioritariamente no ensino fundamental e pré-escolar sendo que as esferas estaduais e federais operarão como coadjuvantes deste processo.

Conforme Kramer (2005, p.18), “a partir dos movimentos sociais, a população conquistou na Constituição de 1988 o reconhecimento do direito de todas as crianças de 0 a 6 anos à educação e do dever do Estado de oferecer creches e pré-escolas para tornar fato esse direito". E assim, as lutas para a consolidação da Educação Infantil foram travadas por pesquisadores e educadores infantis com o desígnio de melhorar a qualidade do atendimento à criança no Brasil.

Logo houve a promulgação da Lei de Diretrizes e Bases da Educação Básica (LDB/96), na qual inclui a Educação Infantil como primeira etapa. Passando a responsabilidade de creches e pré-escolas para as Secretaria Municipais de Educação, o que antes pertencia à área de assistência social, e só então, se tornam instituições educativas. Segundo Lanter (apud KRAMER, 2005, p. 140)

Na década de 1990, parece estar sendo construída, em meio a movimentos da sociedade civil e medidas sancionadas pelo poder publico, uma nova mentalidade em relação ao significado de infância e de educação infantil para a sociedade, sobretudo no que diz respeito ao educador da criança de 0 a 6 anos.

É possível perceber o quanto a discussão sobre a Educação Infantil é recente e consequentemente a formação docente também está em uma fase embrionária. A Lei de Diretrizes e Bases ${ }^{1}$ estabelece que a formação docente mínima para atuar na Educação Infantil está prevista como nível médio na modalidade Normal. Assim, a pesquisa sobre a formação docente cria acentuada relevância, apontando sobre a necessidade de pensar sobre a Educação Infantil.

Neste sentido, a formação de professores tem um percurso histórico e torna-se um objeto de várias pesquisas. É sem dúvidas um eixo fundamental para o desenvolvimento de uma Educação Infantil de qualidade. A profisssionalização e formação docente, tanto inicial quanto continuada, necessita ser pensada criticamente buscando a identidade de ser professor da Educação Infantil.

\footnotetext{
${ }^{1}$ Art. $62^{\circ}$. A formação de docentes para atuar na educação básica far-se-á em nível superior, em curso de licenciatura, de graduação plena, em universidades e institutos superiores de educação, admitida, como formação mínima para o exercício do magistério na educação infantil e nas quatro primeiras séries do ensino fundamental, a oferecida em nível médio, na modalidade Normal. (LDB/96)
} 
A compreensão das bases epistemológicas e teórico-metodológicas da formação de professores irá refletir as concepções que estão sendo enfatizadas na contemporaneidade. E certamente estão diretamente interligadas com o trabalho pedagógico. Os estudos de Filho e Filho (2010, p.45) contribuem propondo:

Que a ampliação do universo cultural, intelectual e humano dos professores possibilita que suas práticas se aproximem cada vez mais das demanda sociais que vão apresentando ao longo de sua profissão e permitem que a reflexão crítica se instale em suas práticas cotidianas.

Tornar o professor pensante e crítico, sendo um ator de sua própria formação certamente implica em um conhecimento teórico cindido com a prática, com um sentido pleno de significações. Nóvoa (2011, p. 17) vem colaborando com a reflexão sobre a relação do professor em sua própria formação, trazendo a prática e a teoria em uma reflexão coletiva, informada e crítica. Os discursos que fazem parte deste contexto são, na sua maioria, descontextualizados da prática e inviáveis de se tornarem realidade;

\footnotetext{
O excesso dos discursos esconde, frequentemente, uma grande pobreza das práticas. Temos um discurso coerente, em muitos aspectos, consensual, mas raramente temos conseguido fazer aquilo que dizemos que é preciso fazer.
}

A atuação docente na Educação Infantil requer análise de aspectos específicos Formatado: Recuo: Primeira linha: com o trabalho com crianças pequenas. Levando-se em consideração que ela é um:

\footnotetext{
Sujeito histórico e de direitos que, nas interações, relações e práticas cotidianas que vivencia, constrói sua identidade pessoal e coletiva, brinca, imagina, fantasia, deseja, aprende, observa, experimenta, narra, questiona e constrói sentidos sobre a natureza e a sociedade, produzindo cultura. (BRASIL, 2010, p. 12).
}

Desta forma há necessidade do conhecimento de uma pedagogia voltada para infância onde o agir pedagógico dos professores foca os anseios infantis.

\section{ABORDAGEM REGGIO EMILIA E SUA FORMAÇÃO DOCENTE}

Após a segunda guerra mundial, em uma pequena cidade ao norte da Itália denominada Reggio Emilia, que fica na região de Emilia Romana, muitos esforços 
foram realizados por idealizadores, educadores, pais e comunidade que se uniram em prol da construção de uma escola que suprisse as necessidades encontradas na época.

A abordagem de Reggio Emilia tem como idealizador, inspirador e organizador Loris Malaguzzi, onde sua ação iniciou-se logo após a segunda guerra mundial, reconstruindo escolas públicas da pequena região de Emilia Romana.

Havia uma grande preocupação em relação às crianças, principalmente pelos acontecimentos políticos e sociais que aconteciam nesse período. Com a união da comunidade de educadores e pais, as pessoas passaram a procurar por uma nova educação que promovesse igualdade de oportunidades para os seus filhos. De acordo com Edwards "atualmente, a cidade financia e opera 11 escolas pré-primárias para crianças de 3-6 anos, bem como 13 centros para crianças de 0-3 anos." (1999, p. 21).

O modelo pedagógico de Reggio Emilia é conhecido e é referência mundial, dessa forma, torna-se relevante buscar aproximações a partir de instituições brasileiras, afim, de colaborar com a melhoria da Educação Infantil no Brasil.

Existem muitas escolas mundo afora que se espelham na proposta de Reggio Emilia, principalmente por ser uma abordagem que traz resultados impressionantes. Outras instituições de Educação Infantil na Itália passaram por transformações pedagógicas, como por exemplo, escolas de Milão, Parma e Pistóia, que trazem diversas considerações para ampliar os estudos na formação profissional em educação infantil na Itália e também no Brasil. (GANDINI, 2002)

Na Itália, de acordo com Gandini (2002, p. 53), a abordagem italiana à Educação Infantil:

\begin{abstract}
$\mathrm{Na}$ década de 70 , quando o atendimento a crianças pequenas estava começando a ser desenvolvido, os professores recebiam treinamento básico tanto como agentes da saúde quanto como professores pré-escolares (sem preparação específica em socialização e educação na primeira infância). Eles estudavam durante três ou quatro anos em escolas profissionais de ensino médio e culminavam seus estudos por volta de 17 ou 18 anos, não recebendo nenhum outro tipo de treinamento.
\end{abstract}

É preciso reconhecer que a formação do professor de Educação Infantil na Itália é bem diferente da qualificação brasileira. Na Itália, de acordo com Loris Malaguzzi (apud EDWARDS, 1999, p. 82):

$\mathrm{O}$ treinamento dura apenas três anos. Um estudante pode matricular-se após terminar a escola secundária e, portanto, obter um diploma aos 17 anos. A preparação é fundamentada sobre nada, nem em termos de uma fundação nas artes liberais ou em estudos profissionais apropriados. 
Segundo Gandini (2002), este treinamento não era adequado, então para que não houvesse decadência na educação de crianças pequenas, fez-se necessário o treinamento em horário de trabalho dos profissionais que já atuavam na área. Para atuar como educador, profissional na Educação Infantil, hoje já é um pouco diferente, pois o profissional precisa ter três anos de educação universitária antes de começar a trabalhar.

Não podemos deixar de citar um marco importante ocorrido na Europa, que é a Declaração de Bolonha (1999).

\begin{abstract}
O processo político e de reformas institucionais, internamente processadas por cada governo nacional ou respectivas entidades descentralizadas, que deverá conduzir ao estabelecimento efetivo do novo sistema europeu de educação superior, até 2010 , incluindo atualmente quarenta e cinco países (isto é, todos os da UE e, ainda, dezoito países europeus não pertencentes à UE), foi designado por Processo de Bolonha. (p.10)
\end{abstract}

O principal aspecto desse tratado entre os países europeus é a redução da duração dos cursos de graduação e a junção da graduação com o mestrado, encurtando o período de formação em ambos para um tempo de cinco anos. (Lima, 2007)

A formação de profissionais Reggio Emilia é constante, além de oferecerem cursos de formação contínua ao longo do ano letivo, a própria rotina nas escolas é um eterno aprendizado, pois se trocam experiências entre as crianças, os pais, a comunidade e os educadores, pois, "consideram que o treinamento de profissionais é essencial." (GANDINI, 2002, p. 51)

É interessante ressaltar que na Itália, assim como no Brasil, são oferecidos cursos de formação continuada no horário de trabalho dos professores. Podemos considerar isso como uma diferença em relação à formação continuada no Brasil. Como cita GANDINI (2002, p. 52):

A fim de apoiar a qualidade das creches, muitas autoridades locais
organizam amplos sistemas de aperfeiçoamento profissional e de
treinamento dos professores em serviço. Esse treinamento em serviço
compensa a baixa qualidade do treinamento anterior que muitas das pessoas
que trabalham com crianças recebem antes de começar a trabalhar.

Nas leituras, pesquisas e reflexões, principalmente no livro "Bambini: a abordagem italiana à educação infantil" percebe-se uma comparação entre escolas que 
seguem a abordagem italiana e ainda com as escolas italianas que deram inicio a essa proposta. Além disso, destaca algumas diferenças entre as escolas Americanas e Italianas, e chama atenção ao dizer que:

\footnotetext{
$\mathrm{Na}$ Itália, os professores devem ter um registro profissional e discutir com seus colegas e supervisores as situações das crianças de que são responsáveis a fim de determinar qual é a maneira mais conveniente de oferecer o melhor atendimento a cada criança. (GANDINI, 2002, p. 44)
}

Segundo Gandini (2002), a Educação Infantil na Itália tem trazido diversas considerações importantes para refletir a educação no Brasil, como por exemplo, em Parma, cidade italiana, existe um programa de desenvolvimento profissional há 20 anos que prima à organização do desenvolvimento profissional e treinamento dos professores em serviço, organizando o trabalho dos coordenadores pedagógicos e professores e, ainda a preocupação com o espaço, tempo, ritmo, materiais e relacionamentos.

Cursos de aperfeiçoamento também são oferecidos no Brasil e geralmente são oferecidos pelas escolas, tanto públicas quanto privadas. Nota-se que esses cursos têm grande importância nas escolas italianas, além de ser um motivador bastante útil, de desenvolvimento profissional contínuo. Após a finalização de cada curso, os professores trocam suas experiências e fazem sua autoavaliação revendo todo seu aprendizado ao longo do aperfeiçoamento profissional.

Coordenadores pedagógicos também dividem seus pensamentos e experiências com os professores a fim de aprimorar os conhecimentos e buscando esse desenvolvimento profissional com professores universitários e administradores de outras cidades, compartilhando conhecimentos e dividindo experiências.

\footnotetext{
Os planos para o desenvolvimento profissional são elaborados hoje em colaboração com outras instituições, as quais levantam questões que emergem de suas diversas esferas de ação e que participam conosco das avaliações no final de cada ciclo de desenvolvimento profissional. (GANDINI, 2002, p. 116)
}

Em Parma, além de atender em 16 creches, existe ainda o Play Center, outro centro de atendimento à educação infantil com uma proposta um pouco diferente, onde os professores e pais trabalham juntos em prol da educação das crianças que frequentavam o espaço, mas "trabalhar junto às crianças e aos pais ao mesmo tempo era 
desconfortável para eles e parecia exigir-lhes um alto grau de competência." (GANDINI, 2002, p. 111)

Para atingir as metas do programa do Play Center em Parma, foi preciso uma reflexão e preparação do plano de desenvolvimento profissional e contratação de novos profissionais, tendo como ponto essencial para a melhoria do espaço, a preparação dos professores e demais funcionários.

Já na cidade de Milão, as famílias passaram por diversas mudanças que dificultavam as escolhas sobre qual serviço educacional seria ideal para os seus filhos, além disso, muitos dados indicavam que as famílias eram isoladas e não tinham conhecimento algum do que eram as crianças, e qual era a relação das escolas com as famílias. No ano de 1985, em Milão, iniciou-se um projeto chamado Tempo para as Famílias, que tinha como conceito de que os profissionais da educação deveriam ser treinados para trabalhar com as crianças e, além disso, modelar e desenvolver atitudes adequadas para com os pais isolados. (GANDINI, 2002)

Existe toda uma preparação dos profissionais em relação às crianças novas que ingressam na escola, principalmente na parte do envolvimento dos professores com os pais e, além disso, no reconhecimento das culturas particulares de cada família.

\footnotetext{
Tempo para as Famílias, baseia-se no conceito de que, a fim de ser útil aos pais, a equipe de trabalho deve ser treinada para trabalhar com crianças pequenas e ser capaz e modelar e desenvolver uma atitude adequada para com os pais. (GANDINI, 2002, p. 94)
}

Na cidade de Pistóia, existe uma grande preocupação com os espaços oferecidos às crianças e também ao envolvimento dos pais, comunidades e com os professores. Além dessa preocupação com os espaços, percebemos o quanto é importante que o professor ofereça uma gama de materiais alternativos a serem utilizados nesses espaços.

\footnotetext{
Sem uma organização bem-pensada, os professores caem em uma repetição mecânica das suas ações, ao invés de elaborar relações novas e produtivas. Entretanto, quando se conta com boas estratégias de planejamento (tais como observação e documentação), os professores podem chegar a conhecer o grupo de crianças com que trabalham e os interesses dessas crianças, propondo-lhe lugares e atividades sem a necessidade de improvisar propostas todas as manhãs. (GANDINI, 2002, p. 122)
}

Todos esses aspectos mencionados anteriormente são voltados ao professor, em que a necessidade de planejar espaços e momentos é refletida na formação contínua 
deste profissional, fazendo com que ele reflita sobre sua docência e seja mais atento as suas experiências e aprendizagens.

\title{
4 AS APROXIMAÇÕES E DIFERENÇAS ENTRE A FORMAÇÃO DE PROFESSORES DA EDUCAÇÃO INFANTIL NO BRASIL E NA ABORDAGEM EM REGGIO EMILIA
}

Partimos do pressuposto que a formação inicial de professores para atuarem na Educação Infantil, tanto no Brasil quanto em Reggio Emilia parte da formação universitária, sendo pré-requisito para a docência. Enquanto práticas públicas de formação de professores o que difere entre os dois países é a formação continuada, quando o professor já está atuando na docência.

$\mathrm{Na}$ Itália a formação continuada de professores é fundamental. Segundo Loris Malaguzzi (apud EDWARDS, 1999, p. 82)

\begin{abstract}
Não temos alternativa, exceto treinar em serviço. Assim como a inteligência torna-se mais vigorosa por meio de seu uso constante, também o papel do professor, o conhecimento, a profissão e a competência tornam-se mais fortes pela aplicação direta. Os professores - como as crianças e todas as outras pessoas - sentem a necessidade de crescer em suas competências, desejam transformar experiências em pensamentos, os pensamentos em reflexões, e estas em novos pensamentos e novas ações. Sentem também uma necessidade de fazer previsões, tentar coisas e então interpretá-las. $\mathrm{O}$ ato de interpretação é o mais importante.
\end{abstract}

O dia-a-dia nestas escolas é um constante aprendizado, as experiências são compartilhadas entre as crianças, os pais, a comunidade e os educadores. Estes professores são os principais atores de suas próprias formações. Os encontros entre professores são trocas de experiências e compartilhamento de conhecimentos. Os coordenadores pedagógicos também participam destes momentos trazendo contribuições com suas experiências. Os registros feitos pelos professores de seus alunos são compartilhados e refletidos por todos os profissionais na escola. Entre os aspectos das reflexões, os profissionais pensam sobre o espaço, tempo, ritmo, materiais e relacionamentos entre adultos e crianças buscando sempre progressos e aprimoramentos.

No Brasil, esta formação continuada recebe vários nomes e diverge em alguns aspectos. Podemos começar refletindo os nomes que já nos trazem ideias das diferenças entre percepções de formação de professores. Kramer (2005, p. 218) nos aponta que: 


\begin{abstract}
No que diz respeito à formação, diversos são os termos que circulam nas redes públicas ou privadas, nas creches, pré-escolas e escolas: "formação permanente" (nome mais antigo), "formação continuada" (consagrada por lei), "formação em serviço" (denominação que preferimos por sua clareza, por se referir à formação de profissionais que já trabalham), "capacitação" (que traz a ideia de dar algo para aqueles que seriam incapazes) ou "reciclagem" (de todos, o pior, por sugerir por considerar que os profissionais podem se descartar da história passada, da experiência vivida e começar tudo de novo).
\end{abstract}

Nesse sentido, já podemos perceber que vários são os entendimentos que no Brasil se tem da formação de professores. Os nomes e o caráter das formações são alterados conforme gestões governamentais, não considerando o que já tem alcançado enquanto conhecimento dos professores.

As esferas governamentais (federal, estadual e municipal) se confundem quanto às exigências da formação continuada. Porém nos últimos anos, segundo Gatti (2009, p. 96) "alguns projetos especiais de formação em serviço realizados com apoio em multimeios vêm respondendo pela elaboração de materiais de apoio à formação para a docência, com certa qualidade, pelos cuidados tomados em sua produção". Mas, historicamente podemos perceber que as mudanças não são imediatas, desta forma mesmo projetos que estão sendo implantados a nível nacional irão surtir efeitos em longo prazo. Ainda segundo Gatti (2010, p. 1358) o fato do Brasil não ter uma base formativa comum, como acontece em outros países, implica em uma fragmentação de conhecimentos entre áreas disciplinares e níveis de ensino.

Existem incertezas que os profissionais da Educação Infantil enfrentam em relação à sua formação e carreira. Em um panorama nacional, Kramer $(2005$, p. 219) nos aponta um desafio que está posto: "como conciliar uma realidade caótica com imperativo de oferecer um atendimento que integre os aspectos físicos, cognitivos, linguísticos, afetivos e sociais da criança entendendo que ela é um ser indivisível”? ${ }^{2}$ Certamente a realidade nacional que trazem cursos esporádicos com caráter emergenciais não trazem resultados significativos para a formação dos profissionais da Educação Infantil. A importância que as secretarias de educação, nas diferentes instancias, dão às propostas pedagógicas revela o pensamento que norteia pedagogicamente a Educação Infantil.

\footnotetext{
${ }^{2}$ Diretrizes Curriculares Nacionais para Educação Infantil. CEB № 1, artigo 3ํ, parágrafo III\Brasília, 1999.
} 
Certamente a formação continuada com uma reflexão efetiva entre discussões sobre a teoria e a prática e o compartilhamento de ideias, como acontece na abordagem Reggio Emília é uma possibilidade enquanto alternativa para uma formação continuada eficaz no Brasil. Ao compartilhar experiências e buscar soluções os professores criar suas próprias metodologias e refletem sobre o acoplamento entre teoria e prática, algo que vem sendo discutido no Brasil.

Também outro aspecto que podemos ressaltar como uma contribuição da abordagem Italiana é a relação que os profissionais da educação desenvolvem com a família. Como podemos perceber "o trabalho com crianças e suas famílias exige que os professores e os profissionais estejam preparados para reconhecer e respeitar essa imensa variedade de sistemas culturais que as famílias representam." (GANDINI, 2002, p.146). Desta forma o trabalho integrado com as famílias desencadeia relações que tendem a melhorar o convívio escolar, o desempenho das crianças e busca dos professores em aperfeiçoamento e ampliação de seus conhecimentos.

Como já discutimos neste estudo algo que é bastante relevante para refletirmos, é a problemática que acompanha diferentes gestões governamentais, os projetos pedagógicos são descartados com novas propostas desconsiderando tudo o que já foi conquistado. Aqui podemos perceber que há uma grande contribuição da abordagem Reggio Emilia que perpassa décadas investindo em uma proposta concreta, apenas aprimorando o que já foi conquistado. Nesta abordagem é importante valorizar as diversas relações, em uma rede de intercâmbios entre crianças e adultos, todos que estão envolvidos no processo educativo, proporcionando uma capacidade autônoma de educar.

\section{CONSIDERAÇÕES FINAIS}

Constatamos então que a formação no Brasil e na Itália não deixa de ser similar em alguns aspectos e em outros podemos apenas refletir como uma possibilidade para a formação de professores da Educação Infantil no Brasil. A pesquisa nos faz refletir aspectos de formação docente e também de formação continuada. Não são questões a serem copiadas e sim refletidas, pesquisadas e discutidas em prol da melhoria da Educação Infantil no Brasil.

No que concerne à formação docente na Itália, é necessário observar alguns pontos que foram abordados no decorrer do artigo, como por exemplo, a formação 
continuada. Da mesma forma que é oferecida na Itália é também no Brasil, mas com algumas diferenças acentuadas.

Certamente abordar a formação de professores na Educação Infantil, no Brasil que está em fase embrionária, é sem dúvidas um estudo amplo que requer pesquisa incessante. Fazer um paralelo com a abordagem Reggio Emilia é algo que instiga a novas pesquisas e nos faz refletir como a formação de professores no Brasil tem a crescer, principalmente na Educação Infantil.

Ainda nesta mesma linha de considerações, a formação continuada oferecida na Itália é um processo contínuo, explorado no horário de trabalho dos professores, pedagogos, administradores e gestores. Além disso, a reflexão da docência é compartilhada em momentos diferentes com os pais das crianças. Após esses cursos de aperfeiçoamentos o profissional faz a sua autoavaliação, busca respostas à sua atuação e conhecimentos adquiridos, e traz as mudanças ao cotidiano.

Indagamos-nos: No Brasil, a formação continuada é oferecida no horário de trabalho do professor? O professor faz essa autoavaliação a fim de melhorar a sua atuação na sala de aula e na relação com os pais das crianças?

O período de finalização de formação inicial para atuação na Educação Infantil no Brasil é de quatro anos, na Itália é diferente. O professor faz a graduação correspondente à área que irá lecionar ao finalizar o seu curso. Além disso, tem a possibilidade de dar continuidade aos estudos e se tornar um Mestre em Educação, no que refere a Proposta de Bolonha de 1999. Esse incentivo traz muitas contribuições ao espaço no qual esse profissional atua. É um professor capaz de refletir sua atuação, pesquisar, dar continuidade a sua formação profissional e pessoal com base nas suas próprias experiências e conhecimentos.

Contudo, o que podemos ressaltar é que a formação do professor deve estar calcada em ampliar "uma intervenção técnica, mas também a uma intervenção política, a uma participação de debates sociais e culturais, a um trabalho continuado junto das comunidades locais" (NÓVOA, 2002, p. 24). Tornando assim a formação responsabilidade também do próprio professor, cuja consciência social deve permear toda ação docente.

\section{REFERÊNCIAS}


BARBOSA, Maria Carmen Silveira; HORN, Maria da Graça Souza. Projetos pedagógicos na educação infantil. Porto Alegre: Artmed, 2008.

GATTI, Bernadete. FORMAÇÃO DE PROFESSORES: CONDIÇÕES E PROBLEMAS

ATUAIS. REVISTA BRASILEIRA DE FORMAÇÃO DE PROFESSORES - RBFP ISSN 1984-5332 Vol. 1, n. 1, p.90-102, Maio/2009.

FORMAÇÃO DE PROFESSORES NO BRASIL: CARACTERÍSTICAS E

PROBLEMAS. Educ. Soc., Campinas, v. 31, n. 113, p. 1355-1379, out.-dez. 2010. Disponível em

$<$ http://www.cedes.unicamp.br>

DECLARAÇÃO de Bolonha. Disponível em: <http://www.mctes.pt/docs/ficheiros/

Declaracao_de_Bolonha.pdf 1999>.Acesso em: 15/08/2012

EDWARDS, Caroline; GANDINI, L. As cem linguagens da criança: as abordagens de Reggio Emilia. Porto Alegre: Artmed, 1999.

FARIA, Ana Lúcia Goulart de; MELLO, Suely Amaral; organizadoras. Territórios da infância: linguagens, tempos e relações para uma pedagogia para as crianças pequenas. Araraquara, SP: Junqueira e Marin, 2007.

FILHO, Altino J. M.; FILHO, Lourival J. M. Formação de professores e trabalho pedagógico na Educação Infantil: considerações propositivas. In: SOUZA, Alba. R. B. de, SARTORI, Ademilde. S., NORONHA, Elisiani C. de S. de F (orgs). Formação docente e práticas: cenários e trajetórias. Florianópolis: Ed. UDESC, 2010

FORMOSINHO, Júlia Oliveira; KISHIMOTO, Tizuko Morchida, (orgs.). Formação em contexto: uma estratégia de integração. São Paulo: Pioneira Thomson Learning, 2002.

FORMOSINHO, Júlia Oliveira; LINO, Dalila; NIZA, Sérgio. Modelos Curriculares para a Educação de Infância: construindo uma práxis de participação. Portugal: Porto Editora, 2007.

GANDINI, Lella; EDWARDS, Carolyn; trad. Daniel Etcheverry Burguño. Bambini: a abordagem italiana à educação infantil. Porto Alegre: Artmed, 2002.

GAUTHIER, Clermont; TARDIF, Maurice (organizadores); tradução de Lucy Magalhães. A pedagogia: teorias e praticas da Antiguidade aos nossos dias. Petrópolis, RJ: Vozes, 2010.

KRAMER, Sonia. Infância e Educação Infantil. Campinas, SP: Papirus, 1999.

2005 .

Profissionais de educação infantil: gestão e formação. São Paulo: Ática,

LIMA, Licínio C.; AZEVEDO, Mário Luiz Neves de; CATANI, Afrânio Mendes. O Processo de Bolonha, a avaliação da educação superior e algumas considerações sobre a universidade nova. Recebido em: 25 de novembro 2007 Avaliado em: 10 de fevereiro de 2008 . 
NOVOA, Antônio. Formação de professores e ação pedagógica. Lisboa: Educar, 2002.

SAVIANI, Dermeval. O problema da Formação de Professores na Itália. In: GOERGEN, Pedro; SAVIANI, Dermeval. Formação de Professores: a experiência internacional sob o olhar brasileiro. São Paulo: NUPES, 1998.

VASCONCELOS, Vera Maria Ramos de (org.). Educação da infância: história e política. Rio de Janeiro: DPeA, 2005. 